\title{
Optimal Configuration and Measurement Analysis of a Solar Heating System Serving an Ordos Residential District
}

\author{
Min ZHOU $^{1}$ and Yuchen XIE and Chunfang YANG \\ China Northwest Architecture Design and Research Institute Co. Ltd, Shaanxi, China
}

\begin{abstract}
In order to solve the contradiction between heating supply and demand in solar energy system in a residential area of Ordos, a solar heating system has been designed, tested, and analyzed for over a month. The main purpose of this paper is to evaluate the primary energy consumption, the carbon dioxide emissions, the initial investment, and the operation costs of the floor radiant and forced convection radiator configuration on the overall performance of the system, and analyzes its potential economic benefits. A parametric analysis has been performed in order to investigate the performance of a solar heating system integrated with dynamic automatic control system upon varying the different terminal device. Results from the present study indicate that the thermal comfort of the proposed system with forced convection radiator configuration is better than the conventional system, And the above four indices reductions from energy efficiency improvements and solar energy supply exceed over $50 \%$.
\end{abstract}

Keywords. Solar heating system, Ordos residential district, energy consumption, carbon dioxide emissions

\section{Introduction}

According to the data show, the area of residential buildings in China is about 52 billion $\mathrm{m}^{2}$, accounting for $82 \%$ of the total area. The energy consumption per year is about 557 million tons of standard coal, the carbon emission per year is about 1.22 billion tons of carbon dioxide [1]. Under the background of the acceleration of urbanization and the improvement of people's living standards, residential buildings in northern heating areas are facing more serious problems of energy shortage and environmental pollution.

The Ordos belongs to the second grade of solar energy resources area, with an average annual sunshine hour of 3008.9 hours and an average annual total solar radiation of $5.9 \mathrm{E} 6 \mathrm{~kJ} / \mathrm{m}^{2}$ [2]. Develop the solar heating technology according to local conditions could improve the quality of the indoor thermal environment and outdoor atmospheric environment in winter, and has a positive effect on the contradiction between energy consumption and ecological environment.

The measured data shows that the low-temperature radiator can meet the requirements of users with continuous heating demand [3]. An On/Off automatic

${ }^{1}$ Corresponding Author, Min ZHOU, China Northwest Architecture Design and Research Institute Co.Ltd, Shaanxi, China; Email: 15353498399@163.com. 
control system for monitoring the return water temperature of the system is proposed, which can reduce the system energy consumption and provide a more comfortable environment [4]. Through the simulation and annual-cost method analysis, scholars conclude that the dynamic solar heating system is more economical [5]. Based on the above research, this paper explores the influence of the automatic control system and terminal units configuration on the overall system performance.

\section{Research Method}

The schematic of the proposed solar heating system is reported in figure 1 .

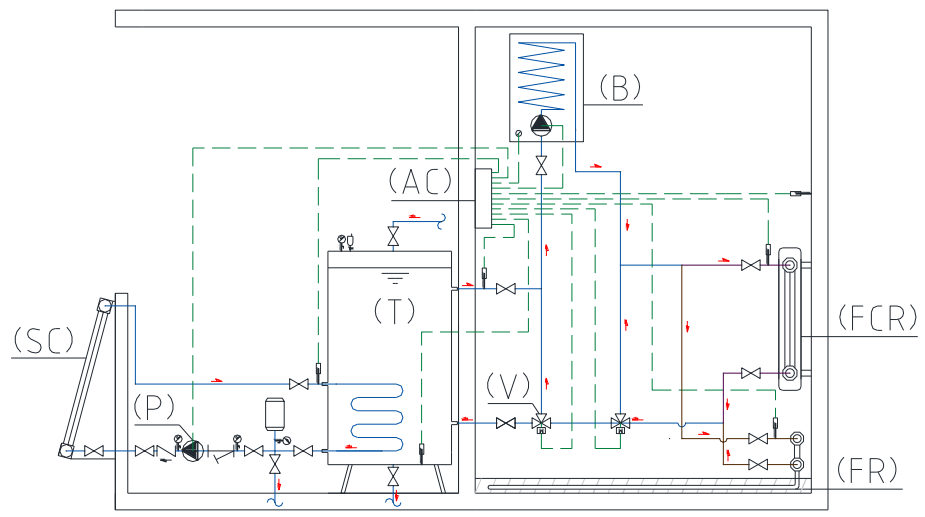

Figure 1. Schematic of the proposed system.

In this figure, the following main components of the system could be identified: Heat-pipe evacuated tube solar collector (SC), heat storage tank (T), floor radiant (FR), forced convection radiator (FCR), electric boiler (B), automatic control system (AC), pumps $(\mathrm{P})$, valves $(\mathrm{V})$ and pipes.

\subsection{Control Logics}

When the dwelling has heating demand and start up the heating system, the control cabinet will receive the signal of each component and send the instruction after PID algorithm calculation.

The signal controlling the switch of the collector circulating pump is the difference between the outlet temperature of the working medium of the solar collector (T1) and the water temperature of the water tank (T2). The collector circulating pump starts when $\mathrm{T} 1-\mathrm{T} 2>3{ }^{\circ} \mathrm{C}$ and closes when $\mathrm{T} 1-\mathrm{T} 2<1.5{ }^{\circ} \mathrm{C}$. Even if there is no heat demand, the collector circulating pump operates with the minimum flow rate of five minutes per hour to avoid freezing of the pipe.

The dwelling might overheat between 9:00 and 19:00, the target of indoor temperature (T3) is fixed at $18^{\circ} \mathrm{C}$ [6]. The automatic control system could maintain the indoor temperature (T3') above the target value by adjusting the water supply temperature (T4'). For the rest of the time, the target of water supply temperature is varies depending on the terminal device. 
The set-point for the water supply temperature is (T4) is varies depending on the terminal device. In floor radiation condition, T4 is fixed at $39{ }^{\circ} \mathrm{C} \mathrm{[7]}$. When $\mathrm{T} 2<37^{\circ} \mathrm{C}$, turn on the electric boiler to heat the water temperature to $43{ }^{\circ} \mathrm{C}$. In the forced convection radiator condition, T4 is fixed at $33{ }^{\circ} \mathrm{C}$. When $\mathrm{T} 2<31{ }^{\circ} \mathrm{C}$, turn on the electric boiler to heat the water temperature to $36^{\circ} \mathrm{C}$.

\subsection{Test Dwelling}

The test dwelling is a cuboid with a length of $4.2 \mathrm{~m}$, a width of $3.0 \mathrm{~m}$, and a height of $3.0 \mathrm{~m}$. The thermal performance parameters of the exterior envelope are reported in table 1 .

Table 1. Thermal performance parameters of the exterior envelope.

\begin{tabular}{lll}
\hline Component & $\begin{array}{l}\text { Heat transfer coefficient } \\
\left(\mathbf{W} / \mathbf{m}^{2} \cdot \mathbf{K}\right)\end{array}$ & Parameter \\
\hline Roof & 0.3 & (i) Color plate (glass cotton sandwich), bulk density is $80 \mathrm{Kg} / \mathrm{m}^{3}$, \\
Exterior & 0.35 & thermal conductivity is $0.056 \mathrm{~W} / \mathrm{m} \cdot \mathrm{K}$. \\
wall & & (ii) Rubber insulation cotton, thermal conductivity is $0.034 \mathrm{~W} / \mathrm{m} \cdot \mathrm{K}$. \\
Window & 2.0 & Plastic single frame Low-E insulating glass. \\
Door & 1.5 & Color plate (glass cotton sandwich).
\end{tabular}

The main characteristics of each component of the heating system are indicated in table 2. The forced convection radiator is mainly composed of a heat dissipation device, power device, fuselage shell, air outlet grille, and control display. Compared with the steel radiator, the water supply temperature demand is reduced by $2 / 3$, and the heat dissipation is increased by $120 \%$.

Table 2. Main characteristics of heating system components.

\begin{tabular}{ll}
\hline Solar thermal collectors & \\
\hline Collector technology & Heat-pipe evacuated tube \\
Gross area of collector $\left(\mathrm{m}^{2}\right)$ & 4.0 \\
Tilted angle / Orientation & $58^{\circ} /$ South \\
\hline Heat storage tank & $1.0 / 1.0$ \\
\hline Volume $\left(\mathrm{m}^{3}\right) /$ Height $(\mathrm{m})$ & \\
\hline Electric boiler & Electric / 3.5 \\
\hline Fuel / Rated capacity $(\mathrm{kW})$ & \\
\hline Floor radiant [6] & PE-RT / de 20 \\
\hline Material / Diameter & 52 \\
Length $(\mathrm{m})$ & 200 \\
Distance between pipes $(\mathrm{mm})$ & 200 \\
Distance between pipe and wall $(\mathrm{mm})$ & \\
\hline Forced convection radiator & $800 / 108 / 500$ \\
\hline Length / Width / Height $(\mathrm{mm})$ & 475 \\
Heat dissipation $(\mathrm{W})$ & $0-5.76$ \\
Air volume $\left(\mathrm{m}^{3} /\right.$ min) & $0-7.2$ \\
Rated capacity $(\mathrm{W})$ & \\
\hline
\end{tabular}

\subsection{Test Conditions}

During the test, December 28 (Case 1), January 3 (Case 2), and January 19 (Case 3) are selected as typical days of 3 conditions of conventional heating system with floor 
radiant, the proposed system with floor radiant and proposed system with forced convection radiator, respectively.

The indoor air temperature measuring points are arranged at the center and four equidistant scattered points of $0.1 \mathrm{~m}, 1.1 \mathrm{~m}, 1.6 \mathrm{~m}, 2.0 \mathrm{~m}, 2.3 \mathrm{~m}$ horizontal layers [8].

\section{Results and Discussion}

\subsection{Measuring Solar Radiation}

The solar radiation intension and the water temperature of the tank under the three test cases are reported in figures 2 and 3.

As shown in figures 2 and 3, the solar radiation intension under the three test cases is the same, the effective value is concentrated in 8:30-16:00, and the peak value is close to $1000 \mathrm{~W} / \mathrm{m}^{2}$. The average peak temperature of the working medium outlet of the solar collector could reach $57^{\circ} \mathrm{C}$. The water temperature of the tank could be increased by $10{ }^{\circ} \mathrm{C}$. The field test results under sunny conditions show that the daily heat gain of the solar collector system (including the heat stored in the tank) is about 19 kWh.

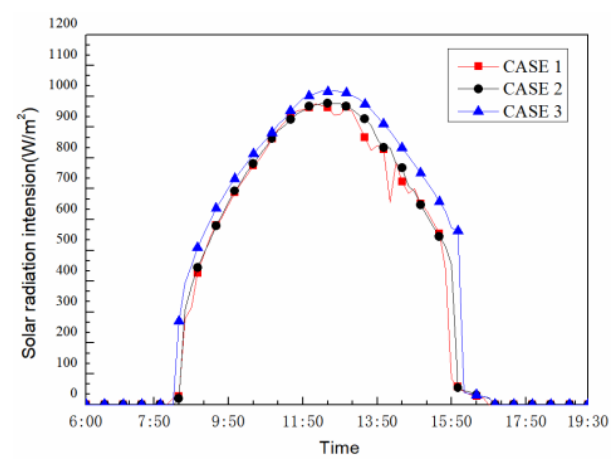

Figure 2. Solar radiation intension.

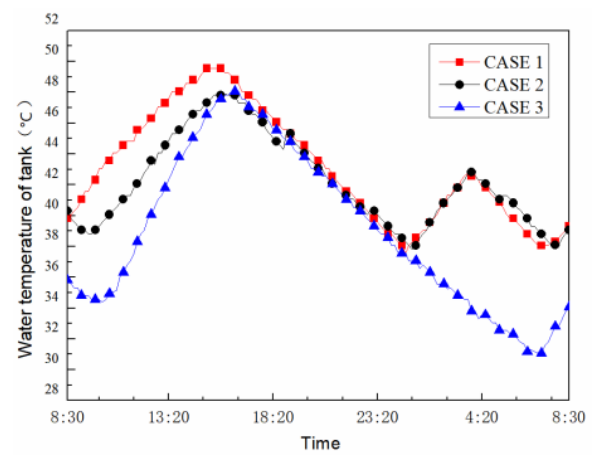

Figure 3. Water temperature of the tank.

\subsection{Auxiliary Heat Supplies}

The water supply temperature of the 3 cases is $39^{\circ} \mathrm{C}, 36^{\circ} \mathrm{C}$, and $29^{\circ} \mathrm{C}$, respectively. As shown in figure 3 , when the sun goes down, the fastest drop rate of water temperature in the tank is Case 1, even if its tank has the highest peak temperature.

According to the setting of the automatic control system and the demand of water supply temperature, the time to use up the same heat of Case 3 is 6 hours longer than the other two cases, operation time of the electric boiler under Case 3 is 2 hours shorter than the other two cases.

\subsection{Indoor Temperature}

The distribution of indoor vertical and horizontal air temperature is reported in figures 4 and 5 . The box diagram could reflect the temperature fluctuation. A, B, C, D, and E 
represent the northwest, northeast, center, southwest, and southeast measuring points respectively.

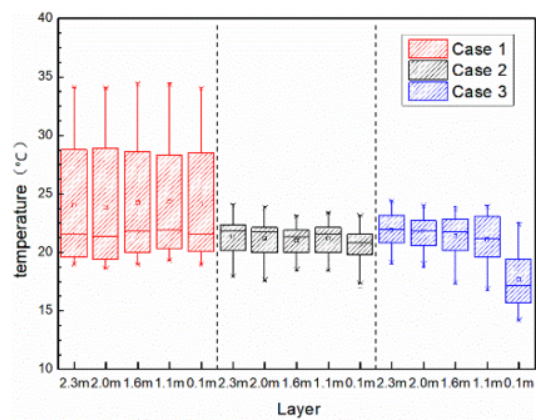

Figure 4. Distribution of indoor vertical air temperature.

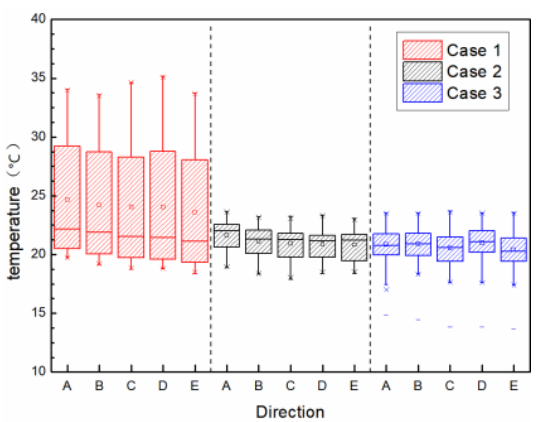

Figure 5. Distribution of indoor horizontal air temperature.

Because the water supply temperature is not controlled in Case 1, the indoor air temperature will overheat under direct sunlight in the daytime (the highest value is $34{ }^{\circ} \mathrm{C}$ ), and the average temperature is about $2.6{ }^{\circ} \mathrm{C}$ higher than the other two cases. The temperature fluctuated greatly (the value is about $15^{\circ} \mathrm{C}$ ) in the whole day, but the temperature difference between the horizontal layers of adjacent heights was small (the value is no more than $3{ }^{\circ} \mathrm{C}$ ). Compared with Case 1 , Case 2 could maintain the temperature in a good range by controlling the change of water supply temperature during the period when overheating might occur. Under this case, the indoor air temperature fluctuation and the temperature difference between the horizontal layers of adjacent heights are the minima, and the thermal comfort of humans is the best. The air outlet height of the forced convection radiator is $1 \mathrm{~m}$, so the temperature of $0.1 \mathrm{~m}$ horizontal layer is the lowest, the temperature difference with other layers is about $3.4^{\circ} \mathrm{C}$. Except for the $0.1 \mathrm{~m}$ horizontal layer, the temperature fluctuation and difference of other surfaces are small, and the average temperature is about $0.5^{\circ} \mathrm{C}$ higher than that of Case 2.

Due to the influence of the cold air infiltration in the gap between door and window, the temperature values of the southeast measuring point are the lowest. Because of the uniform heat dissipation of the floor radiation, the temperature value of the northwest measuring point is greatly affected by the heat dissipation of the control cabinet, and its temperature value is the highest. The difference is that the heat dissipation of the forced convection radiator is uneven, the temperature value of the southwest measuring point closest to the radiator is the highest.

\subsection{Energy Analysis}

The primary energy consumption between the proposed and conventional heating systems has been performed employing the index named Primary Energy Saving (PES) [9]: 


$$
\begin{gathered}
\mathrm{PES}_{1}=\frac{\left(\mathrm{E}_{\mathrm{p}}^{\mathrm{C}}-\mathrm{E}_{\mathrm{p}}^{\mathrm{FR}}\right)}{\mathrm{E}_{\mathrm{p}}^{\mathrm{C}}} \\
\mathrm{PES}_{2}=\frac{\left(\mathrm{E}_{\mathrm{p}}^{\mathrm{C}}-\mathrm{E}_{\mathrm{p}}^{\mathrm{FCR}}\right)}{\mathrm{E}_{\mathrm{p}}^{\mathrm{C}}} \\
\mathrm{PES}_{3}=\frac{\left(\mathrm{E}_{\mathrm{p}}^{\mathrm{FR}}-\mathrm{E}_{\mathrm{p}}^{\mathrm{FCR}}\right)}{\mathrm{E}_{\mathrm{p}}^{\mathrm{FR}}}
\end{gathered}
$$

where, $\mathrm{E}_{\mathrm{p}}^{\mathrm{FR}}$ is the primary energy consumption of Case $2, \mathrm{E}_{\mathrm{p}}^{\mathrm{FCR}}$ is the primary energy consumption of Case 3, and $\mathrm{E}_{\mathrm{p}}^{\mathrm{C}}$ is the primary energy consumption of Case 1. The values of $E_{p}^{C}, E_{p}^{F C R}$, and $E_{p}^{F R}$ of Eq.1-3 have been calculated according to the following formula [10]:

$$
\mathrm{E}_{\mathrm{p}}=\left(\alpha f+\frac{1-f}{\eta}\right) Q
$$

where, $f$ is the contribution rate of solar energy $\left(f_{\mathrm{C}}, f_{\mathrm{FR}}\right.$, and $f_{\mathrm{FCR}}$ are equal to 0.53 , 0.59 and 0.78$), \alpha$ is the power consumption of the pump and fan ( $\alpha_{\mathrm{FR}}$ is equal to 0.02 , $\alpha_{\mathrm{FR}}$ is equal to 0.03), $\eta$ is the energy efficiency of the equipment (equal to 0.96), $Q$ is the total daily heat supply of the system, including the heat supply of the collector system and the auxiliary heat source $\left(\mathrm{Q}_{\mathrm{C}}, \mathrm{Q}_{\mathrm{FR}}\right.$, and $\mathrm{Q}_{\mathrm{FCR}}$ are equal to 18,14 , and 7 $\mathrm{kWh}$ ).

Case 3 has the highest solar energy contribution rate and the most obvious energysaving effect. Compared with the other two systems, the PESs are $62.1 \%$ and $51.4 \%$, respectively.

\subsection{Emissions Analysis}

The global carbon dioxide equivalent emissions between the proposed and conventional heating systems have been performed employing the energy output-based emission factor approach $\left(\Delta \mathrm{CO}_{2}\right)$ [9]:

$$
\begin{aligned}
\Delta \mathrm{CO}_{2,1} & =\frac{\mathrm{m}_{\mathrm{CO}_{2}}^{\mathrm{C}}-\mathrm{m}_{\mathrm{CO}_{2}}^{\mathrm{FR}}}{\mathrm{m}_{\mathrm{CO}_{2}}^{\mathrm{C}}} \\
\Delta \mathrm{CO}_{2,2} & =\frac{\mathrm{m}_{\mathrm{CO}_{2}}^{\mathrm{C}}-\mathrm{m}_{\mathrm{CO}_{2}}^{\mathrm{FCR}}}{\mathrm{m}_{\mathrm{CO}_{2}}^{\mathrm{C}}}
\end{aligned}
$$




$$
\Delta \mathrm{CO}_{2,3}=\frac{\mathrm{m}_{\mathrm{CO}_{2}}^{\mathrm{FR}}-\mathrm{m}_{\mathrm{CO}_{2}}^{\mathrm{FCR}}}{\mathrm{m}_{\mathrm{CO}_{2}}^{\mathrm{FR}}}
$$

where, $\mathrm{m}_{\mathrm{CO}_{2}}^{\mathrm{FR}}$ is the mass of global equivalent carbon dioxide emitted by Case $2, \mathrm{~m}_{\mathrm{CO}_{2}}^{\mathrm{FCR}}$ is the mass of global equivalent carbon dioxide emitted by Case 3 , and $\mathrm{m}_{\mathrm{CO}_{2}}^{\mathrm{C}}$ is the mass of global equivalent carbon dioxide emitted by Case 1 . The values of $\mathrm{m}_{\mathrm{CO}_{2}}^{\mathrm{C}}, \mathrm{m}_{\mathrm{CO}_{2}}^{\mathrm{FR}}$, and $\mathrm{m}_{\mathrm{CO}_{2}}^{\mathrm{FCR}}$ of equations (5)-(7) have been calculated according to the following formula:

$$
\mathrm{m}_{\mathrm{CO}_{2}}=\gamma \mathrm{E}_{\mathrm{p}}
$$

where $\gamma$ is the $\mathrm{CO}_{2}$ equivalent emission factor for electricity production (equal to 573 $\mathrm{gCO}_{2} / \mathrm{kWh}$ ). The daily carbon dioxide emission saved by the forced convection radiator heating system is $3.9 \mathrm{~kg}$, which accounts for only $1 / 2$ of the floor heating system. Case 3 has better environmental benefits.

\subsection{Economic Analysis}

\subsubsection{Initial Investment}

The initial investment in the heating system is reported in table 3.

Table 3. Initial investment.

\begin{tabular}{lc}
\hline Component & Cost $\mathbf{( \$ )}$ \\
\hline Heat-pipe evacuated tube solar collector & 309.4 \\
Heat storage tank & 77.4 \\
Electric boiler & 139.2 \\
Heating circulating pump & 38.7 \\
Heat collecting circulating pump & 38.7 \\
Floor radiant & 80.0 \\
Forced convection radiator & 139.2 \\
\hline
\end{tabular}

When the terminal device of the heating system is floor radiant, the initial investment is $\$ 681.3$, when the terminal device of the heating system is forced convection radiator, the initial investment is $\$ 742.6$.

\subsubsection{Operating Costs}

The operating costs of the heating system have been calculated according to the following formula [9]:

$$
\mathrm{OC}=\tau \mathrm{E}_{\mathrm{p}}
$$

where, $\tau$ is the electric charge of Ordos (equal to $0.08 \$ / \mathrm{kWh}$ ). The daily operating cost of the three systems is $\$ 1.4, \$ 1.1$, and $\$ 0.5$, respectively. 


\subsubsection{Annual-Cost Analysis}

The annual cost of the heating system has been calculated according to the following formula:

$$
Z_{d}=\frac{i(1+i)^{m}}{(1+i)^{m}-1} K+O C
$$

where, $\mathrm{K}$ is the initial investment, $\mathrm{OC}$ is the yearly operating costs, $\mathrm{i}$ is the interest rate (equal to 0.08 ), $\mathrm{m}$ is the service year (equal to 15 years). The annual cost of the three systems is $\$ 547.6, \$ 444.6$, and $\$ 264.0$, respectively. Case 3 has the lowest annual cost and the best economic benefit.

\section{Conclusion}

A parametric analysis has been performed to investigate the performance of a solar heating system integrated with a dynamic automatic control system upon varying the different terminal devices. The measured results highlighted that: (a) the thermal comfort of the proposed system is better than the conventional system; (b) the proposed system with forced convection radiator could reduce the primary energy consumption (up to $62.1 \%$ ), carbon dioxide emissions (up to 62.1\%) and annual-cost (up to $51.8 \%$ ) in comparison to the conventional heating system with floor radiant; (c) the proposed system with forced convection radiator could reduce the primary energy consumption (up to 51.4\%), carbon dioxide emissions (up to 51.4\%) and annual-cost (up to $40.6 \%$ ) in comparison to the conventional heating system with floor radiant.

\section{Acknowledgments}

This work was financially supported by the National Key Research and Development Project of China (No.2018YFC0704506), National Key Research and Development Program (No.2019YFE0100300-12), the Opening Fund of State Key Laboratory of Green Building in Western China (No.LSKF201902).

\section{References}

[1] BP Statistical Review of World Energy https:/www.bp.com/zh_cn/china/reports-andpublications/_bp_2019-_html.

[2] Wu L, Du L, Wang J and X Sun Distribution characteristics and evaluation of potential solar energy resources in Yulin Region of Northern Shaanxi Province Bulletin of Soil and Water Conservation 33 (01) $238-242$.

[3] Li Q N 2009 Application Research on Radiator Heating System Working at Low Temperature (Harbin Institute of Technology).

[4] Mokhtari F, Loukarfi L and Belhamel M 2012 Use of on/Off mode for regulation of a solar heating system for building Procedia Engineering 33 313-320.

[5] Bu Y 2006 Research on Application Technology of Solar Heating System in Residential Buildings in Small Towns (Tongji University).

[6] Sattari S and Farhanieh B 2006 A parametric study on radiant floor heating system performance Renewable Energy 31 (10) 1617-1626.

[7] Sibbitt B, McClenahan D, Djebbar R, Thornton J, Wong B, Carriere J and Kokko J 2012 The performance of a high solar fraction seasonal storage district heating system-five years of operation 
Energy Procedia 30 856-865.

[8] GB 50785-2012 Evaluation Standard for Indoor Thermal Environment in Civil Buildings.

[9] Angrisani G, Couldelli M, Roselli C, Russo A, Sasso M and Tariello F 2017 A small scale polygeneration system based on compression/absorption heat pump Applied Thermal Engineering 114 1393-1402.

[10] Yu G and Zhou J 2015 Effects of auxiliary heat sources on energy efficiency of active solar heating systems Heating Ventilating Air Conditioning 45 (05) 12-16. 